\title{
GENERATION AND ASSESSMENT OF HIGH RESOLUTION DIGITAL SURFACE MODEL BY USING UNMANNED AIR VEHICLE BASED MULTICOPTER
}

\author{
S. Gülci a,*, T. Dindaroğlu ${ }^{\mathrm{a},}$, R. Gündoğan ${ }^{\mathrm{b}}$ \\ ${ }^{a}$ Kahramanmaras Sutcu Imam University, Faculty of Forestry, Department of Forest Engineering, 46100, Kahramanmaras, Turkey. \\ (sgulci, turgaydindaroglu@ksu.edu.tr)

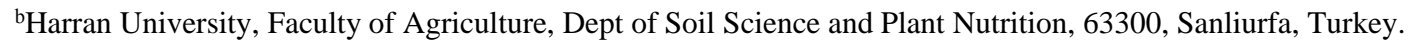 \\ (rgundogan@harran.edu.tr)
}

KEY WORDS: Hexacopter, Remote sensing, Air photo, Mission planner, DSM

\begin{abstract}
:
Unmanned air vehicle systems (UAVSs), which are presently defined as effective measuring instruments, can be used for measurements and evaluation studies in fields. Furthermore, UAVs are effective tools that can produce high-precision and resolution data for use in geographic information system-based work. This study examined a multicopter (hexacopter) as an air platform to seek opportunity in generating DSM with high resolution. Flights were performed in Kahramanmaras Sutcu Imam University Campus area in Turkey. Pre-assessment of field works, mission, tests and installation were prepared by using a Laptop with an adaptive ground control station. Hand remote controller unit was also linked and activated during flight to interfere with emergency situations. Canon model IXSUS 160 was preferred as sensor. As a result of this study, as mentioned previous studies, .The orthophotos can be produced by RGB (Red-green-blue) images obtained with UAV, herewith information on terrain topography, land cover and soil erosion can be evaluated.
\end{abstract}

\section{INTRODUCTION}

Generating digital surface models (DSMs) by unmanned air vehicles (UAV) and mountable systems become an appropriate and common method for scientific assessments and also for engineering related works. UAV classes, the specification of mounted sensors, flight height and speed may vary according to the aim and specific scope of the research(Watts et al., 2012; Wings et al., 2014; Gülci and Akay, 2016). The UAV-based studies that include before and after the flight stages, should be well designed for the quality of produced photogrammetric data and security (Akgül et al., 2016).

\section{MATERIAL AND METHODS}

\subsection{Study area}

The study was performed in Kahramanmaras Sutcu Imam University Campus area in Turkey. Land use type of the main study has been preferred to use as agricultural activity. The land, where has an erosion potential, has different slope classes (Figure 1).

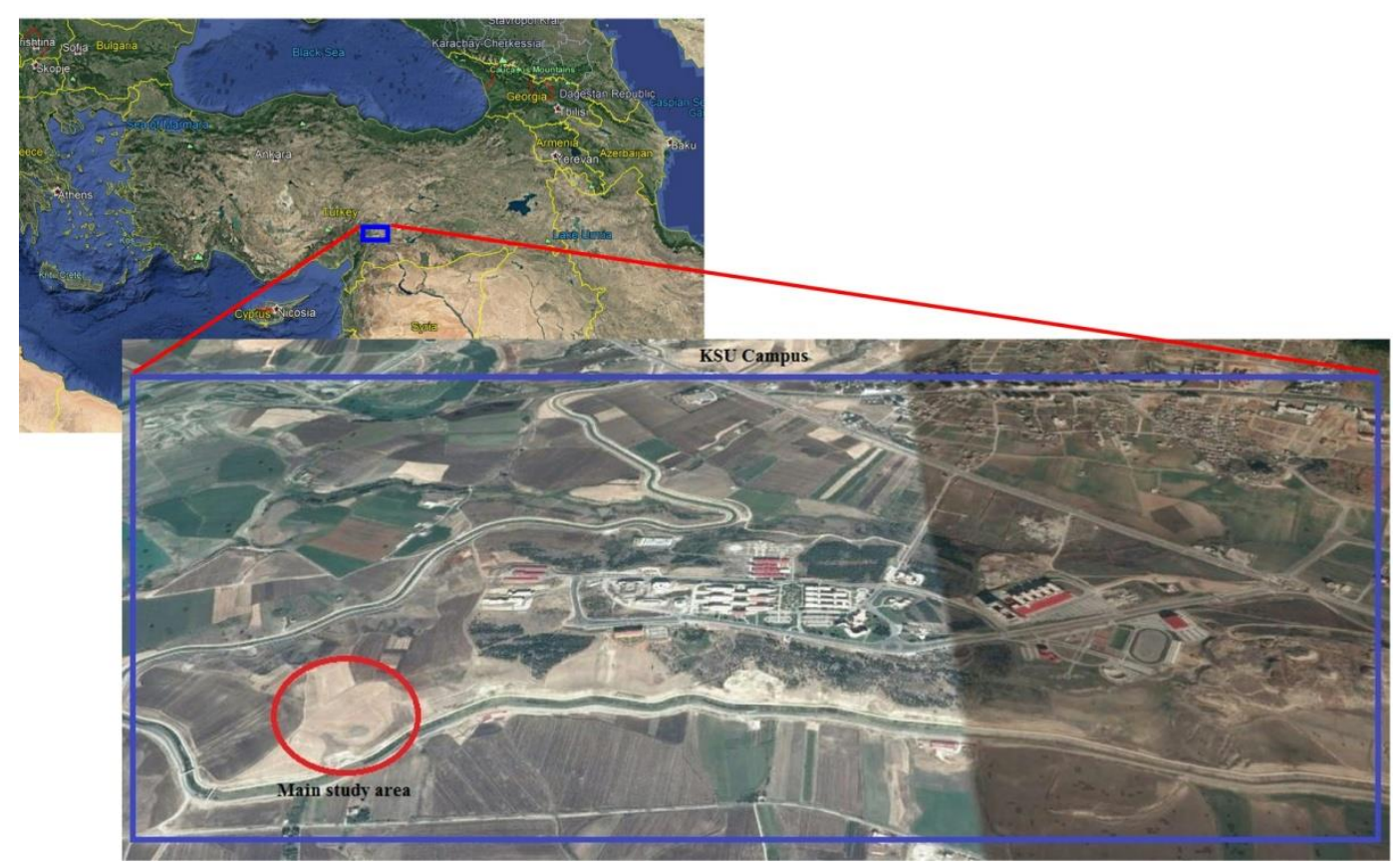

Figure1.Geographical location of the study area 


\subsection{Field Study}

This study examined a multicopter (hexacopter) as an air platform. Canon model IXSUS 160 which sensor mounted on hexacopter has a record ability on the secure digital (SD) Card inside the camera, was mounted on air platform (Figure 2;3) (Remondino et al., 2011; Chao et al., 2016). Total of 8 ground control points were surveyed by using Global navigation satellite system (GNSS), which has almost millimeter accuracy in spatial measurements, and these points were considered as reference point in geo-rectification.

Mission planner, which is an open-source interface software, provided flight mission to acquire block pattern. The flight altitude was defined $100 \mathrm{~m}$, and the ratio of side and forward overlaps were planned as $80 \%$ (forward) and $60 \%$ (side).

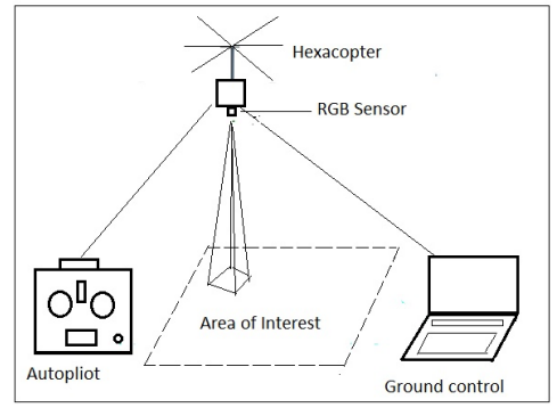

Figure 2. UAV system structure (after Chao et al., 2016)

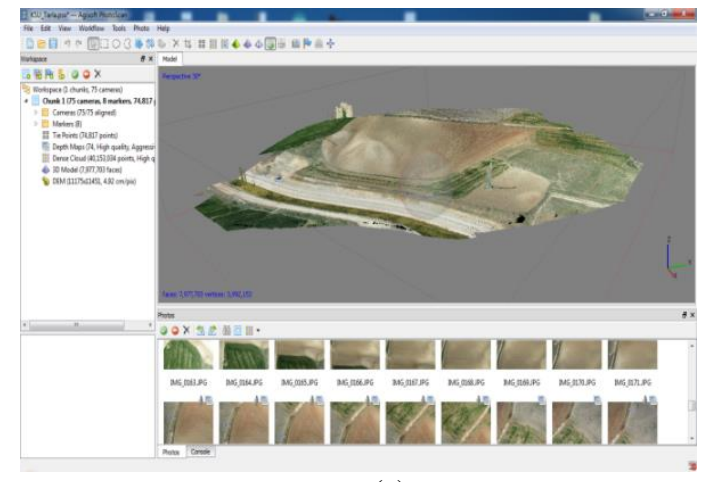

(a)

Figure 4. Interface views of software used in image processing. (a) Agisoft PhotoScan, (b) CloudCompare

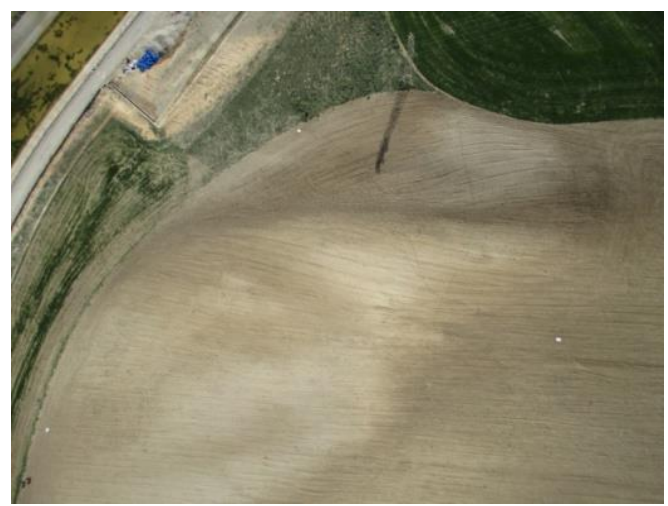

\subsection{Image Process}

Processing and analysis of images were performed with PhotoScan, which works under the base of SfM (Structure from motion) approaches, and CloudCompare, which is an opensource interface (Figure 4) (Westboy et al.,2012; Gülci et al., 2017; Cloud, 2017). Image processing steps by PhotoScan can be summarized as 1 . identification of common points and creation of photo plane for block (alignment of photo), 2. point cloud generation, 3. image meshing, and 4. image texture (Agisoft, 2016). The initial options on image processing stages were implemented on PhotoScan as shown in Table 1.

\begin{tabular}{lc}
\hline \multicolumn{1}{c}{ Process } & Accuracy/Quality/Mode/Method \\
\hline Photo alignment & High \\
Point cloud & Ultra high \\
Mesh & High \\
Texture & Ortophoto \\
\hline
\end{tabular}

Table 1. Preferred work standards in image processing

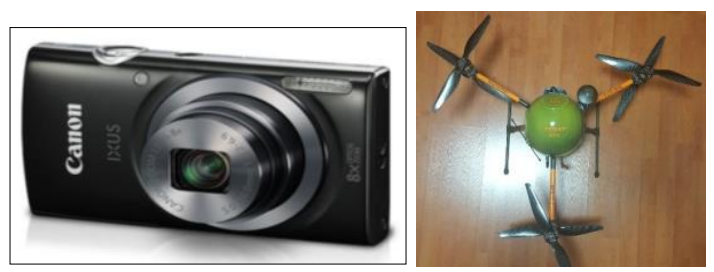

Figure 3. Air platform (hexacopter) and preferred sensor (Canon IXSUS 160)

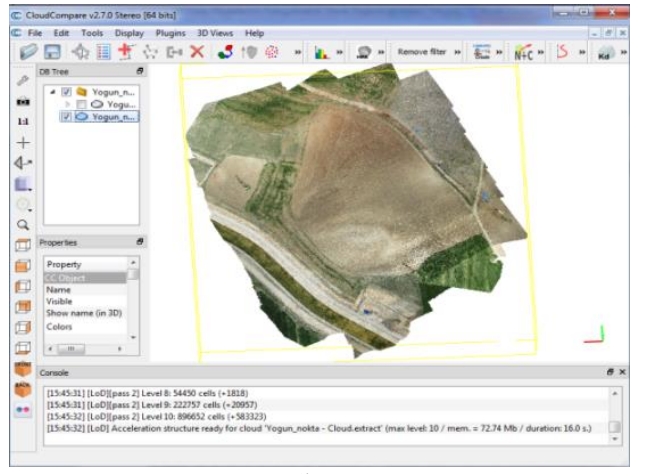

(b)

Figure 5. Air photo samples obtained by Hexacopter. 

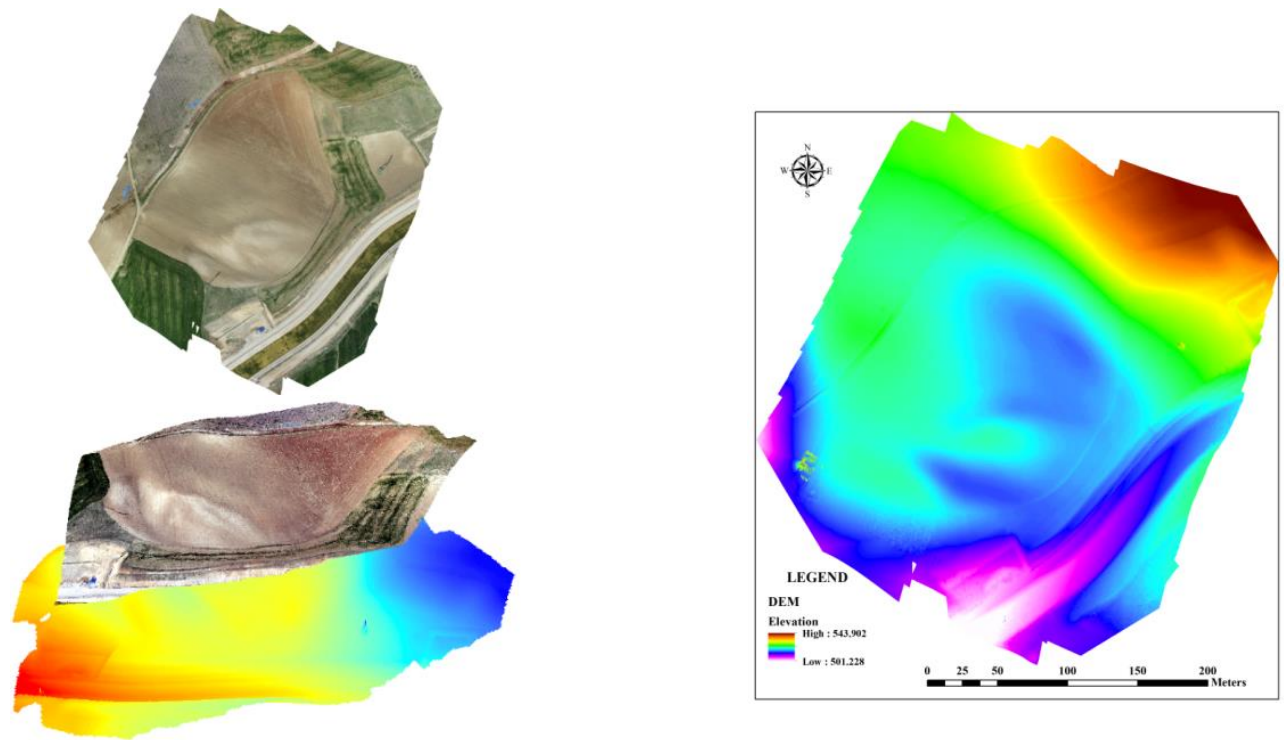

Figure 6. Generated DSM and ortophoto by using UAV

\section{RESULTS AND FINDINGS}

At the end of flight, total of 75 air photos were obtained from sensor (Figure 5). The alignment of photo was completed with considering 74817 tie points detected. Then, analysis of dense cloud point generation figured out, totally, as 40.153 .034 points $\left(413.129\right.$ points $\left./ \mathrm{m}^{2}\right)$. Estimated image acquisition height was $111 \mathrm{~m}$. The resultant resolution of the DSM and orthophoto were $4.92 \mathrm{~cm}$ and $2.46 \mathrm{~cm} /$ pix (Table 2; Figure 6).

\begin{tabular}{lc}
\hline \multicolumn{1}{c}{ Data type } & Value \\
\hline Total photo & 75 \\
Average flight altitude & $111 \mathrm{~m}$ \\
Orthomosaic resolution & $2.46 \mathrm{~cm} /$ pixel \\
Study area & $96500 \mathrm{~m}^{2}$ \\
Camera stations & 75 \\
Tie points & 74817 \\
Projection & 237911 \\
Error & 0.928 pixel \\
\hline
\end{tabular}

Table 2. Block adjustment results

Briefly, topographic maps with high resolution can be derived from the use of UAV systems. It provides convenience for researchers by removing time and area constraints (Akgül et al., 2016). The orthophotos can be produced by RGB (Red-greenblue) images obtained with UAV, herewith information on terrain topography, land cover and soil erosion can be evaluated (d'Oleire-Oltmanns et al., 2012; Bendinget al., 2014; Inan and Öztürk, 2016).

\section{ACKNOWLEDGEMENT}

This study was conducted in the frame of $114 \mathrm{R} 052$ project funded by TUBITAK

\section{REFERENCES}

Agisoft, 2016. "Agisoft PhotoScan." Accessed January 17, 2016. http://www.agisoft.com/.

Akgül, M., Yurtseven, H., Demir, M., Akay, A.E., Gülci, S, Öztürk, T., 2016. Usage opportunities of generating digital elevation model with unmanned aerial vehicles on forestry.
Journal of the Faculty of Forestry Istanbul University. 66(1): 104-118. doi:10.17099/jffiu.23976

Bending, J, Andreas, B., Simon, B., Janis, B., Silas, E. and Georg, B., 2014.Estimating Biomass of Barley Using Crop Surface Models (CSMs) Derived from UAV-Based RGB Imaging, Remote Sens. 6, pp. 10395-1041.

Chao, H., Jensen, A.M., Han,Y., Chen, Q.Y., McKee, M., 2016. Unmanned Aircraft Systems AggieAir: Towards Low-cost Cooperative Multispectral Remote Sensing Using Small. Advances in Geoscience and Remote Sensing. Chapter 22. Editted by Gary Jedlovec www.Intechopen.com. doi: $10.5772 / 8333$

Cloud, 2017. http://www.cloudcompare.org/doc/wiki/ index.php?title=Main_Page

d'Oleire-Oltmanns, S., Irene, M., Klaus, D.P., Johannes B.R., 2012. Unmanned Aerial Vehicle (UAV) for Monitoring Soil Erosion in Morocco. Remote Sens. 4, pp. 3390-3416.

Gülci, S., Akay, A.E., 2016. Using thermal infrared imagery produced by unmanned air vehicles to evaluate locations of ecological road structures. Journal of the Faculty of Forestry Istanbul University, 66(2), pp. 698-709.

Gulci, S., Yurtseven, H., Akgul, M., 2017. Assessment of preflight block planning for structure from motion studies using micro-unmanned air vehicles. Journal of the Faculty of Forestry Istanbul University 67(2): xxx-xxx. [Accapted article]

İnan M., Öztürk T., 2016. Orman yollarının durumunun değerlendirilmesinde düşük maliyetli yersel fotogrametrinin kullanimi, VI. Uzaktan Algilama ve CBS Sempozyumu (UZALCBS 2016), ADANA, TÜRKIYE, 4-7 Ekim 2016, cilt.1, no.1, ss.275-279.

Remondino, F., Barazzetti, L., Nex, F., Scaioni, M., Sarazzi, D., 2011. UAV photogrammetry for mapping and $3 \mathrm{~d}$ modelingcurrent status and future perspectives. International Archives of the Photogrammetry, Remote Sensing and Spatial Information Sciences, 38(1), pp. C22.

Watts, A.C., Ambrosia, V.C., Hinkley, E.A., 2012. Unmanned aircraft systems in remote sensing and scientific research: classification and considerations of use. Remote Sens. 4, pp.1671-1692. 
Westoby, M. J., Brasington, J., Glasser, N. F., Hambrey, M. J., \& Reynolds, J. M. 2012. 'Structure-fromMotion'photogrammetry: A low-cost, effective tool for geoscience applications. Geomorphology, 179, pp. 300-314.

Wing, M.G., Burnett, S., Johnson, S., Akay, A.E., Sessions, J., 2014. A Low-cost unmanned aerial system for remote sensing of forested landscapes. International Journal of Remote Sensing Applications. 4(3), pp. 113-120. 